Association for Information Systems

AIS Electronic Library (AISeL)

Wirtschaftsinformatik 2021 Proceedings

Track 18: Future of Digital Markets and

Platforms

\title{
How to Design IloT-Platforms your Partners are Eager to Join: Learnings from an Emerging Ecosystem
}

Tobias Moritz Guggenberger

Technische Universität Dortmund

Fabian Hunke

Karlsruher Institut für Technologie

Frederik Möller

Technische Universität Dortmund

Anne-Catherine Eimer

Karlsruher Institut für Technologie

Gerhard Satzger

Karlsruher Institut für Technologie

See next page for additional authors

Follow this and additional works at: https://aisel.aisnet.org/wi2021

Guggenberger, Tobias Moritz; Hunke, Fabian; Möller, Frederik; Eimer, Anne-Catherine; Satzger, Gerhard; and Otto, Boris, "How to Design IloT-Platforms your Partners are Eager to Join: Learnings from an Emerging Ecosystem" (2021). Wirtschaftsinformatik 2021 Proceedings. 6.

https://aisel.aisnet.org/wi2021/GFuture18/Track18/6

This material is brought to you by the Wirtschaftsinformatik at AIS Electronic Library (AISeL). It has been accepted for inclusion in Wirtschaftsinformatik 2021 Proceedings by an authorized administrator of AIS Electronic Library (AISeL). For more information, please contact elibrary@aisnet.org. 


\section{Presenter Information}

Tobias Moritz Guggenberger, Fabian Hunke, Frederik Möller, Anne-Catherine Eimer, Gerhard Satzger, and Boris Otto 


\title{
How to Design IIoT-Platforms your Partners are Eager to Join: Learnings from an Emerging Ecosystem
}

\author{
Tobias Moritz Guggenberger ${ }^{1,3}$, Fabian Hunke ${ }^{2}$, Frederik Möller ${ }^{1,3}$, \\ Anne-Cathrine Eimer ${ }^{2}$, Gerhard Satzger ${ }^{2}$, and Boris Otto ${ }^{1,3}$ \\ ${ }^{1}$ TU Dortmund University, Chair for Industrial Information Management, Dortmund, Germany \\ \{Tobias.Guggenberger,Frederik.Moeller,Boris.Otto\}@tu-dortmund.de \\ ${ }^{2}$ Karlsruhe Institute of Technology, Karlsruhe, Germany \\ \{Fabian.Hunke,Gerhard.Satzger\}@ kit.edu \\ Anne-Cathrine.Eimer@student.kit.edu \\ ${ }^{3}$ Fraunhofer ISST, Dortmund, Germany \\ \{Tobias.Moritz.Guggenberger,Frederik.Moeller,Boris.Otto \}@isst.fraunhofer.de
}

\begin{abstract}
Building and sustaining a successful platform business remains one of the biggest challenges in the age of digitalization and platformization, particularly in the manufacturing industry. The art of managing the partner ecosystem to create and distribute mutual benefits depends on the design of the platform - thus, on the implemented mechanisms and functionalities, typically complemented by third-party applications. Therefore, it is eminently important to attract potential partners to enter the ecosystem. With this article, we provide substantial insight into the case of an emerging platform and its respective ecosystem of stakeholders. We analyze their individual requirements, abstract them into general key requirements, and finally develop design principles. Thus, our research, on the one hand, extends the current knowledge of platform literature with new, generalized knowledge about platform design, especially in the development phase. On the other hand, we contribute to the emerging field of participant attraction previously focusing on complementors.
\end{abstract}

Keywords: IIoT-Platform, Platform Ecosystems, Digital Transformation, Case Study, Design Principles.

\section{Introduction}

The diffusion of digital technology is changing society and, in addition to that, the economic organization and products, services, and business models [1, 2]. In the industrial context, the continuous digitization of manufacturing processes and assets leads to cyber-physical-systems, which are the root of the industrial Internet of Things (IIoT) [3]. IIoT refers to the industrial things (e.g., machines, trucks, or loading carriers) connected via information and communication technologies [3, 4]. Platforms are an essential architectural component for the IIoT as they facilitate the control and, in addition to that, the optimization of these manufacturing systems [3-6]. Therefore, the 
design of IIoT-platforms is directly correlated to such systems' efficiency and effectiveness [3,5], making the study attractive for both scholars and practitioners.

Platforms, which are internally used, focus on integrating innovative capabilities to create value through network externalities within and between different platform sides in the service network [7-9]. The set of agents related to a platform is referred to as the platform ecosystem [10-12]. Although the platform construct has been a subject of interest for the last decades, research specifically focused on IIoT-platforms is rare [1315]. From an economic perspective, there are fundamental differences between the market characteristics of the prominent B2C platforms and IIoT-platforms in the manufacturing industry. The market size, fragmentation, and competition influence the necessary strategies and tactics for firms to establish successful platforms [13, 16].

Moreover, in contrast to consumer platforms, industrial platforms rely heavily on cross-side network effects and collaboration, which the platform owner needs to foster precisely $[17,18]$. Additionally, since the actors and their resources are different, value co-creation processes occur that might be hard to understand from the incumbent's perspective [19]. Following this argumentation, IIoT-platform owners face a massive "chicken-and-egg problem" [7] that we define as the scalability problem of industrial platforms.

While growing the ecosystem, platform owners need to manage varying interests and boundary conditions and implement those in the platform's architecture and processes. For example, governance and orchestration are two significant issues for value creation and capturing $[18,20]$. The latter is one of the strongest incentives for ecosystem participation and the primary focus when designing a platform. Beyond that, the integration of resources leads to value co-creation between service providers and consumers, which remains an unfamiliar issue for traditionally product-oriented firms [21]. The platform design is central for the development and economic success of such ecosystems. It is important to integrate both the technical and business perspective while studying and engineering digital platforms [22]. Our study contributes to this specific aspect, as we propose design principles for an artifact that meets these conditions.

Thus, manufacturing industries must develop high-performance platforms with functionalities that address customers' individual needs to be successful in digitization. In order to achieve this, the requirements of the respective groups must be identified and analyzed with regard to their integrability. For this purpose, we report on a casethat gives us an excellent, in-depth insight into the individual requirements of ecosystem participants. With the interview technique, we were able to overview both the static and dynamic components of the ecosystem regarding the interaction among the participants. To interpret our results reasonably, we used qualitative content analysis to structure our interpretative process using theoretical knowledge from different technical and managerial platform literature streams. Based on this, we can propose design principles for IIoT-platforms. We have, therefore, defined the following research question:

Research Question (RQ): How should an IIoT-platform be designed to deploy a stakeholder friendly environment? 
The remainder of the article is structured as follows. First, we give an overview of the relevant theoretical background, which encompasses the digital transformation of the manufacturing industry, the role of platforms in the fourth industrial revolution, and the economic foundations of successful platform businesses. This is followed by an overview of the conducted research method. Subsequently, we present the study's findings, including generalized design principles we have derived from those findings. Lastly, we discuss our contributions and the limitations of our research and suggest possible further research endeavors.

\section{Theoretical Background}

\subsection{Digitization of Manufacturing and the Role of IIoT-Platforms}

Using modern technologies in industrial contexts to digitize assets aims at the cyberphysical integration of production sites, which scholars refer to as the fourth industrial revolution or Industry 4.0 [23]. Those digital factories are part of the industrial Internet of Things (IIoT) and require novel means for control that rely on digital platforms [4, 5]. A network layer connects the physical resources from an architectural viewpoint and makes them controllable and, thus, optimizable through digital platforms $[3,6]$.

Depending on the discipline, a platform can either refer to technological or economic models [22]. In information systems and management research, a platform is commonly defined as a technical architecture that facilitates the integration of capabilities and resources $[12,22,24]$. They connect different agents at different levels of analysis that result from the scope of the platform (internal, supply chain-,, and industry-wide [22]). Digital platforms are modular technological systems that comprise a stable core and varying auxiliary modules, which enhance the potential usefulness of such systems [15, 24]. Integrating the core and periphery is realized through boundary resources, such as technological interfaces (e.g., APIs) or Software Development Kits (SDKs), which are opening the possibility for third-party developers to contribute such complementary modules, e.g., applications $[25,26]$. Influenced by the success of prominent digital platforms, like Facebook and Amazon, their potential is evaluated in almost any sector [24, 27].

In manufacturing industries, IIoT-platforms are of particular interest for smart factories [15] since they are at the heart of these concepts [5]. The key functions of the IIoT-platforms are "event processing, event notification, and real-time analytics, to name a few" [4]. Furthermore, they allow integrating other systems, such as Enterprise Resource Management (ERP) or Manufacturing Execution Systems (MES). Besides that, data management, data analysis, and decision making are basic modules of the digital representation of such systems [6]. Compared to software platforms such as SAP, which are also opening themselves for external developers to an ecosystem, IIoTPlatforms focus on extending the range of functions and integrating digital assets as the core of the value proposition $[5,28]$. 


\subsection{Building Successful Digital Platform Ecosystems}

From a business perspective, the opening of an internal or supply chain platform to other actors has several economic implications that rely on, simplified, the foundation of a multi-sided market around the platform [29]. The economic view of platforms as enablers of transactions is closely related to the engineering view, which focuses on technology $[22,30]$. Indisputably, economic success can only be achieved through adequate technology. These multi-sided markets are characteristic of network externalities, which can be direct or indirect [7-9]. A growing number of agents in one market-side, commonly exemplified by the increasing value of communication technology (e.g., WhatsApp vs. Signal) when user numbers rise, generates the prior. The latter depends on the rise of agents in a different market-side. For example, the value of an Android phone increased when the number of applications exploded, and vice versa. The value of Nokia declined fast when the developers turned their backs on them. The most important result is that firms have to make sure to "get both sides on board" [7, p. 991]. Unfortunately, this is easier said than done because it requires specific actions to attract participants joining the ecosystem through incentives based on governance mechanisms [20,31]. Thus, a growing number of complementors leads to increased customization potential.

Within platform ecosystems, coopetition, and value co-creation occur, making new strategies necessary [2, 10, 12, 21, 32]. Distinct types of ecosystems are distinguishable that differ in their specific structure and characteristics [11]. They have in common that positive network effects do not necessarily arise until specific actions are undertaken, e.g., developing a governance structure and orchestration [18, 20]. So does Hurni et al. [33] emphasize governance as a key for the dedication of complementors to attract them investing in the partnership with the platform owner. Vice versa, a platform will lose its importance for developers if their decision-making rights are very limited, and their coordination costs are high. Other scholars refer to the motivation of complementors to join a platform ecosystem as basically driven by the platform's "innovativeness and its commercial capital" [34].

Above that, it remains unclear for the potential participants how they contribute to the value co-creation and their benefits, respectively [22, 27]. Beyond the creation of value, the capturing of value remains an important issue for the platform leader and complementors [18].

In conclusion, the economic success of a platform relies on scaling their ecosystem, generating network effects to create value, and facilitating capturing the value for the platform leader and every other participant, respectively. Moreover, the technological perspective acts as an enabler for successful platforms. While the role of attracting the complementor as a source of innovative capabilities for the platform has been researched intensively, the overarching perspective of different perspectives on the attractiveness of a platform has so far been neglected. Thus, this research contributes to a better understanding of the platform design related to ecosystem participants needs and, foremost, the motivational interaction between the different needs that can be described as the first step towards an ecosystem tension management. 


\section{$3 \quad$ Research Method}

\subsection{Study Design}

The design principles originate from a qualitative interview study with 15 experts from industry practice. The interview is an accepted research method to collect data engraved in industry practitioners' experiences and social settings $[35,36]$. We selected interview partners based on various stakeholder roles (see Section 4) to inquire about the most comprehensive view on emerging ecosystems in IIoT-platforms. The stakeholders reflect the emerging ecosystem of an IIoT-platform established in 2015, a spin-off of an established incumbent machine manufacturer (see Section 4). A semi-structured interview guide guided each interview. It is the most goal-oriented option, contrary to the open interview (with no restrictions) and structured interviews as the research retain structure and comparability, yet leaves enough flexibility to adjust to ad hoc situations in the interview [39].

\subsection{Data Collection and Analysis}

We had the opportunity to study representative participants of the emerging platform ecosystem directly with multiple interviews (see Table 1) and indirectly through secondary data. The management of the platform owner and the machine manufacturer actively supported the project as sponsors and provided us with "legitimacy and credibility" [37, p. 588]. As a result, all participants greatly assisted us, especially with arranging interview dates and informal meetings, which was very valuable. In addition to collecting primary data, we had the opportunity to attend team meetings and analyze secondary data (e.g., current surveys and internal documents). For an appropriate study of the phenomenon, we conducted 15 formal interviews, which we recorded and transcribed. Also, we used the informal meetings and internal documents to understand the context further.

Table 1. Interview Details ${ }^{1}$

\begin{tabular}{|l|l|l|}
\begin{tabular}{l} 
Stakeholder \\
\multicolumn{2}{|l|}{ Role }
\end{tabular} & $\begin{array}{l}\text { Duration } \\
\text { (h) }\end{array}$ \\
\hline \multirow{3}{*}{$\begin{array}{l}\text { Platform } \\
\text { Owner }\end{array}$} & Pre-Sales Manager/Consultant & $00: 41$ \\
\cline { 2 - 3 } & Consultant & $00: 45$ \\
\cline { 2 - 3 } & Consultant & $00: 59$ \\
\hline \multirow{4}{*}{$\begin{array}{l}\text { Machine } \\
\text { Manufacturer }\end{array}$} & Partner Management & $00: 50$ \\
\cline { 2 - 3 } & Project Leader & $00: 35$ \\
\cline { 2 - 3 } & Product Manager Internal App Development & $00: 41$ \\
\cline { 2 - 3 } & Customer Guard & $01: 01$ \\
\hline
\end{tabular}

${ }^{1}$ All interviews were conducted in German and translated into English here. Verbatim quotes are coded as follows: 2 letters referring to the stakeholder +4 letters referring to the role (e.g. PP.Cons for a consultant of the platform owner). 


\begin{tabular}{|l|l|l|}
\hline & Industry 4.0 Expert in Communication \& Security & $00: 48$ \\
\hline \multirow{4}{*}{ Complementor } & Data Scientist, Predictive Maintenance & $00: 47$ \\
\cline { 2 - 3 } & Managing Director, Maintenance & $00: 50$ \\
\cline { 2 - 3 } & Managing Director, Digital Solutions & $00: 59$ \\
\cline { 2 - 3 } Customer & Managing Director, Maintenance & $00: 46$ \\
\hline & Managing Director, Sheet Metal Processing & $00: 32$ \\
\cline { 2 - 3 } & Industry 4.0 Expert, Manufacturer & $00: 37$ \\
\cline { 2 - 3 } & Managing Director, Sheet Metal Processing & $01: 28$ \\
\hline
\end{tabular}

We conducted a qualitative content analysis to analyze the transcribed interviews using MaxQDA. Qualitative content analysis [38, 39] is a flexible [39] research technique that allows the analysis and interpretation of meanings from qualitative data $[38,40]$, e.g., interview transcripts, as it delivers "replicable and valid inferences from texts [...]" [38, p. 18]. The analytical process focuses on the coding of elements of the documents [40]. Central for every qualitative content analysis is the system of categories, which can either be deducted from theory, inductively derived from the text, or determined by a combined method [39].

To verify the quality of the entire coding process and determine its validity, we measured the intercoder reliability, which we calculated based on four counter coded interviews. The criterion of intercoder reliability verifies the correspondence between two coders. It is examined whether the assignment of the predefined codes between two different coders to non-segmented material finds an agreement. We use Cohen's kappa to measure the degree of the agreement following Brennan and Prediger's [41] model for its calculation and reached a value of $\mathbf{0 . 6 4}$ - suggesting a substantial agreement between the two coders [42].

In conclusio, the coding seemed valid regarding the four counter-coded interviews. Therefore, the analysis of the interviews is completed, and we present the results of the analysis in the next section.

\subsection{Design Principle Generation}

This research aims to derive design principles to generate prescriptive knowledge regarding the design of IIoT-platforms, i.e., codified and formalized design knowledge that guides practitioners to design artifacts more efficiently and, ultimately, successfully [43]. Thus, rather than describing artifact design descriptively, they explicitly intend to advise designers to achieve a pre-determined set of goals [44]. As there is no standard way to derive design principles, some use Action Design Research (ADR) (e.g., [45]) or follow established DSR methods (e.g., [46]). Following the recommendations of [47], we develop supportive design principles that we formulate by eliciting meta-requirement for each stakeholder in the IIoT-platform's ecosystem. Meta-requirements, in that regard, are general requirements that do not address a single instance of artifact implementation but rather a class of artifacts [48]. Subsequently, each design principle requires to address at least one meta-requirement, a relationship, which is usually termed value grounding [44]. Although there is a variety of formulation approaches (for an overview, see [49]), we chose to formulate our design 
principles according to the linguistic template of [43]. It demarcates constituent elements and, thus, provides excellent potential for rigorous formulation. We deviate from the exact linguistic wording if this would hinder comprehensibility. The template is as follows [43 p. 4045]:

"Provide the system with [material property-in terms of form and function] in order for users to [activity of user/group of users-in terms of action], given that [boundary conditions—user group's characteristics or implementation settings]."

The template refers to material properties that explicate what the artifact should consist of to be able to execute the intended action. Lastly, as their environment demarcates design principle instantiation, they are only supposed to be valid in specific boundary conditions [43].

\section{The Case of an Emerging IIoT-Platform: Requirements Towards the Platform Owner}

\subsection{Case Description}

The platform under research connects several stakeholders we consider in our research. The groups are described below:

- Platform owner: Responsible for the provision of the infrastructure, both technically and organizationally. He assumes the role of the mediator and ensures that all platform members can achieve their goals.

- Machine manufacturer: The machine manufacturer, in this case, must be seen in close cooperation with the platform owner. The primary goal of the machine manufacturer is to offer its customers a better service and thus to increase customer satisfaction.

- Complementor: The complementor is a software company that supplements the platform with additional applications (Third-party Apps).

- Customer: Small-to-medium-sized manufacturing company (sheet metal processing), which is under pressure to increase its efficiency steadily. As a result, the customer is forced to have increasing competences in the field of digitalization.

From a technical perspective, the platform enables the vertical and horizontal integration of different systems through applications, e.g., for the horizontal level: ERPand MES-System integration. Furthermore, applications allow functionalities to include the overview of machine utilization, material consumption, or the current machine program in real-time. Custom applications can extend those with more specific functions.

As the platform brings the stakeholders together and bundles their needs to create benefit for all of them, the definition of a multi-sided platform fits the above-described use case. A lack of technological maturity dominates the general environment in which the company operates due to the industry structure itself. For example, the direct 
connectivity of machines is currently not possible due to a high degree of heterogeneity. Therefore, it is necessary to develop alternative models to achieve these objectives. Nevertheless, the number of digital services provided by complementors is continuously increasing. Accordingly, a platform for the provision of digital solutions and data could be a suitable approach. Conflicts between the different stakeholders due to varying expectations of the platform are possible. For this reason, it is essential to identify the requirements and expectations to find out which potential conflict areas can arise. Finally, by elaborating on the guidelines, the core for developing the platforms can be defined.

\subsection{Requirements Towards the Platform Owner}

The case study provided in-depth insights into the mindset, problems, and requirements of the various stakeholders involved in an IIoT-platform. In this section, we first outline the industry-specific challenges for IIoT-platforms and then describe the key requirements derived from the qualitative content analysis, which form the basis for the design principles defined in the subsequent section.

We identified three deeply grounded challenges in the branch: First, many challenges of implementing IIoT-platforms result from the traditional branch of mechanical engineering. That leads to at least two obstacles. Cultivated over decades, the organizational blindness leads companies to oversee opportunities that digital innovations can offer:

"In many places, there are many doubts or I would sometimes say just not necessarily a lot of experience, and then something new is always abstract and in doubt a bit more difficult." (TP.DiSo)

Beyond that, the branch is diametrically opposed to the agile branch of the Software Industry, which can lead to communication issues and refusal of innovation, which may be perceived as risks, as a third-party manager confirms:

"It is a change, a service-related change, many say: "I'm not gonna take that risk. This is probably a general problem, which you will probably hear often in other industrial-software areas as well." (TP.DiSo)

Second, similar to the first challenge, the digitally enabled business models are unfamiliar to the traditional ones and require new perspectives on, e.g., cooperation or value propositions. Applying business models or constellations from other digital sectors are hardly imaginable:

"[...] I must never become dependent on a platform if there is no other way. With the 'Apple App Store', there is no other way, but anywhere else, we will always look for alternatives through our strategy. Unless we see that the benefit is so great, then I might do that, but until then, I don't see a problem with that." (MM.PaMa)

The third challenge is the technical diversity of the industry. IT infrastructure and technical systems, e.g., machinery, are very heterogeneous, which leads to increased effort for integrating the systems. That is apparent to the platform owner's consultants:

"What makes it difficult from my point of view at the moment is that we always operate in an environment in which other IT systems already exist. That can be an ERP that can be IT system XY [...]" (PP.Cons) 
Based on the case findings, we formulated meta-requirements that we generalize and condense to key requirements [50]. Further, we clustered the key requirements into thematic categories that address Technical, Organizational, Service, or Economic issues. Table 2 shows the final list of key requirements.

Table 2. Meta-Requirements (MR) and Key-Requirement (KR) derived from the study.

\begin{tabular}{|c|c|c|c|}
\hline MR & Key Requirement & Stakeholder & Description \\
\hline \multirow{3}{*}{ 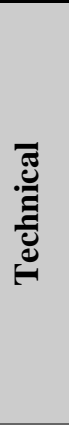 } & $\begin{array}{l}\text { Standards for } \\
\text { Integration (KR1) }\end{array}$ & Customer & $\begin{array}{l}\text { Refers to the necessity of standards } \\
\text { for technical integration of platform } \\
\text { actors. }\end{array}$ \\
\hline & $\begin{array}{l}\text { Provided data and } \\
\text { interfaces (KR2) }\end{array}$ & Complementor & $\begin{array}{l}\text { The platform must provide data and } \\
\text { efficient interfaces for further } \\
\text { development of products and } \\
\text { services. }\end{array}$ \\
\hline & $\begin{array}{l}\text { Storage capacities } \\
\text { (KR3) }\end{array}$ & Complementor & $\begin{array}{l}\text { The platform should offer } \\
\text { transactions, integration, and cloud } \\
\text { storage. }\end{array}$ \\
\hline \multirow{3}{*}{ 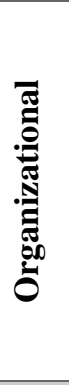 } & $\begin{array}{l}\text { Strong customer } \\
\text { involvement }(\mathbf{K R 4})\end{array}$ & General & $\begin{array}{l}\text { Further development and operation } \\
\text { of the platform depends on a high } \\
\text { level of customer involvement. }\end{array}$ \\
\hline & $\begin{array}{l}\text { Central cooperation } \\
\text { in one place (KR5) }\end{array}$ & Complementor & $\begin{array}{l}\text { The platform designed should } \\
\text { enable users to manage operational } \\
\text { processes cooperatively. }\end{array}$ \\
\hline & $\begin{array}{l}\text { Providing } r \text { security } \\
\text { and } \\
\text { (KR6) }\end{array}$ & Complementor & $\begin{array}{l}\text { The platform must ensure a trusted } \\
\text { and secure environment for the user. }\end{array}$ \\
\hline \multirow{3}{*}{ 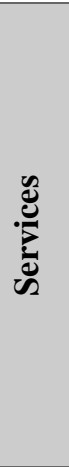 } & $\begin{array}{l}\text { Partner } \\
\text { Management (KR7) }\end{array}$ & Customer & $\begin{array}{l}\text { The value of complementary } \\
\text { services and products must } \\
\text { constantly increase through active } \\
\text { partner management. }\end{array}$ \\
\hline & $\begin{array}{lr}\text { Provision } & \text { of } \\
\text { solutions } & \text { for } \\
\text { different business } \\
\text { areas (KR8) }\end{array}$ & Customer & $\begin{array}{l}\text { Refers to the need for a diversified } \\
\text { service offering that covers diverse } \\
\text { business needs. }\end{array}$ \\
\hline & $\begin{array}{l}\text { Personal Support } \\
\text { (KR9) }\end{array}$ & Customer & $\begin{array}{l}\text { Refers to personal and individual } \\
\text { advice from qualified service } \\
\text { personnel. }\end{array}$ \\
\hline \multirow{2}{*}{ 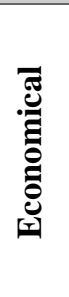 } & $\begin{array}{l}\text { Cost reduction and } \\
\text { service } \\
\text { improvement as } \\
\text { added value (KR10) }\end{array}$ & General & $\begin{array}{l}\text { Refers to the main value proposition } \\
\text { of the platform. }\end{array}$ \\
\hline & $\begin{array}{lr}\text { Efficiency } & \text { gain and } \\
\text { cost } & \text { savings } \\
\text { (KR11) } & \end{array}$ & Customer & $\begin{array}{l}\text { Refers to the main requirement on } \\
\text { the customer side. }\end{array}$ \\
\hline
\end{tabular}




\begin{tabular}{|l|l|l|l|}
\hline $\begin{array}{l}\text { Attractive and cost- } \\
\text { effective business } \\
\text { model (KR12) }\end{array}$ & Customer & $\begin{array}{l}\text { Refers to the business model of the } \\
\text { platform owner. It is necessary to act } \\
\text { in a particularly cost-effective } \\
\text { manner in order to be competitive. }\end{array}$ \\
\hline $\begin{array}{l}\text { Ensuring revenue } \\
\text { from performance } \\
\text { (KR13) }\end{array}$ & $\begin{array}{l}\text { Using a performance-based } \\
\text { approach so that the value of higher } \\
\text { performance is shared with the } \\
\text { platform owner. }\end{array}$ \\
\hline
\end{tabular}

\section{Design Principles for IIoT-Platforms}

Based on key requirements derived in Table 2, we formulated design principles as a response to them [47]. Following the example of [51], Table 3 lists seven design principles with short titles and corresponding key requirements that they address. In the following, we will elaborate on the design principles in more detail and provide explicatory rationales for their existence.

Table 3. Design principles and Key Requirements.

\begin{tabular}{|l|l|}
\hline Short title of Design Principles (DP) & $\begin{array}{l}\text { Addressed Key } \\
\text { Requirements }\end{array}$ \\
\hline DP1: Low Entry Barriers & 1,2 \\
\hline DP2: Focus on transactions and cloud-services & 2,3 \\
\hline DP3: Trusted collaboration between platform actors & $4,5,6$ \\
\hline DP4: Active ecosystem management & 7 \\
\hline DP5: Customizable solutions and support & 8,9 \\
\hline DP6: Value proposition: Efficiency for cost savings & $10,11,12$ \\
\hline DP7: Gain-sharing approach & 13 \\
\hline
\end{tabular}

\subsection{Technical Cluster}

Design Principle 1: Provide the system with low entry barriers in order for users to switch easily to/from your platform at the lowest cost and effort-intensive technical adjustments or problems, given the technical design of platform integration components.

Rationale: In platform literature, switching costs refer to the effort one platform user must undertake (e.g., in installing new software) to change a utilized platform. For competing platforms, having low entry barriers to access platforms is key [52]. The design principle refers to two components. First, those entry barriers must be small in terms of technical effort. That means that the platform should provide commonly used technological standards and interfaces so that the actors can integrate quickly, rather than having to adopt new technologies (KR1). The second component addresses the attractiveness of the platform for complementors to contribute products and services. Thus, the platform should provide suitable interfaces (e.g., APIs and respective 
documentation) and rich data (KR2). The latter is of crucial importance for developers to create individualized products and services that rely on the needs of the customers. That will finally lead to a higher ecosystem value. The relevance of DP1 is also underpinned by the multi-homing literature, which indicates, on the one hand, that the quality of a complement is lower when ported onto a platform whose architecture is complex [53]. A reduction of complexity can be achieved by the use of standards and interfaces, as this prevents an adaptation of the complements. On the other hand, the absence of compatibility between different platforms weakens the competition and increases costs [54]. Additionally, research suggests that limiting access, which increases the probability of single-homing, damages at least one side of the market [55].

Design Principle 2: Provide the system with both transaction enablement and cloudservices in order for users to have an integrated platform for most common operations, given the design of the technical service structure of the platform.

Rationale: The platform should provide mechanisms for the transactional exchange of services and products on the platform that utilizes an underlying cloud-infrastructure. That is necessary to enable independent access to data and services and allows for modern technical integration (KR3). These services must use commonly accepted interfaces and (anonymous) user data in order for developers to, e.g., train their Machine Learning Algorithms (KR2).

\subsection{Organizational Cluster}

Design Principle 3: Provide the system with centralized collaboration capabilities between all user groups in order for users to interact easily with their customers or partners, given the design of the interaction mechanism of the platform.

Rationale: The third design principle addresses KR4, KR5, and KR6. First, the design principle prescribes that customers must be involved on the platform to facilitate goal-oriented integration into value-creating mechanisms (KR4). Second, the actors should be able to work collaboratively on executing business processes to facilitate the collaborative generation of innovation and contributions (KR5). Lastly, for collaboration to work, the platform must ensure secure exchanges between actors to have the necessary trust in the platform infrastructure to join the platform ecosystem and contribute to it (KR6).

\subsection{Services Cluster}

Design Principle 4: Provide the system with the capability of active ecosystem management of partners, complementarities, and value sharing, in order for users to ensure the greatest possible benefit to users in the long term.

Rationale: Actor management is a vital issue in platform organization and requires tools for their active design $[14,56]$. Thus, the design principle prescribes the integration of mechanisms for the active management of ecosystem actors. The overarching goal is to foster and make more convenient complementation of the core platform components with additional products and services. Finally, this will lead to 
the increased overall attractiveness of the ecosystem through high value delivered by strong partners (KR7).

Design Principle 5: Provide the platform with customizable solutions and support functions in order to satisfy the needs of each user in the most effective manner and to avoid creating entry barriers given the design of platform service structures.

Rationale: The IIoT-platform should offer highly individualized and, thus, diversified products and services to different customer segments with shared requirements. In that, the degree of individualization must pay into tailoring offerings to customer demands so that they apply to a variety of business needs (KR8). Additionally, the IIoT-platform should provide the customer with individualized support services, which cover all areas that could hinder customers from integrating into the platform ecosystem. Thus, these support services must cover a range from technical integration to working on the platform. Simply put, each actor must receive support services on each level of the integration process (KR9).

\subsection{Economical Cluster}

Design Principle 6: Provide the platform with a focus on the value proposition on multiple layers to increase service efficiency and enable cost reductions for customers to give the design of the superordinate value proposition of the platform.

Rationale: Attractive value propositions are at the core of platform business models and contain multiple layers $[2,57]$. First, the platform's value should clearly indicate for its users that using the platform results in reducing cost and improvement of services. That means that users should identify opportunities either for optimization or improve their service-level quality (KR10). That requirement is mirrored by the customer side, which should be provided with a high degree of efficiency gains to decide to join and use the platform (KR11). On the platform owner side, the platform should be run economically so that a clear cost-benefit advantage is identifiable and contributes to the platform's survival. This is of particular importance, as poor efficiency sets rigid limits to scalability (KR12).

Design Principle 7: Provide the platform with a gain-sharing approach to strengthen the community in order for users to rely on a broad diversification of risks and to distribute the platform's benefit amongst all participants.

Rationale: The platform should pursue a gain-sharing logic that builds on performance-based mechanisms. In that, most performing stakeholders would gain a larger share of revenue generated in the platform ecosystem. Overall, if the gain of the platform ecosystem rises at large, there should be distribution mechanisms considering stakeholder contributions adequately. That approach also includes the platform owner. Finally, such mechanisms result not only in sharing value but also in decreasing the risk of high expenses or fees in low-performance periods (KR13). 


\section{Discussion}

\subsection{Conclusion and Implications}

The success of digitalization of the manufacturing industry lies in the usage of platforms that are used to connect, control, and optimize IIoT-systems. Although these systems' relevance is known, as they represent an important architectural component, we lack an understanding of how such platforms need to be designed for success and how to get "everyone on-board". Scholars already investigated single aspects, such as the attraction of complementors and launching strategies [58], but we lack in a comprehensive and overarching understanding of how to bring those economic issues together and how this will influence the design decisions of a particular platform.

We bridge the gap between different perspectives, at least the technological and economical, to offer a nascent design theory in the form of design principles derived from a specific case that is representative for the IIoT-platforms. Therefore, we have first identified several requirements from the platform's stakeholders and abstracted them to design principles that work for the class of IIoT-platforms. Furthermore, we defined four clusters of design decisions regarding technical, organizational, service, and economic decisions. Thus, this allows us to, on the first hand, contribute to the growing platform literature that deals with value creation, value capture, and, foremost, attracting participants. On the other hand, we provide substantial guidelines for practitioners, which are planning to develop an IIoT-platforms to extend their current value propositions. In the following, we present our scientific and managerial contributions in detail.

Our work provides prescriptive guidelines for designing an IIoT-platforms and considers multiple perspectives in terms of scientific contributions. Accumulating prescriptive knowledge is an issue of paramount importance in design science [59]. Thus, it extends the current knowledge base of platform literature with new, generalized knowledge about platform design, especially in the fast-growing field of platform design, which is of high importance. Also, our research may lead other researchers to complement, cross-validate, or extend our design principles, as to contribute to closing additional gaps in platform design literature.

In terms of managerial contributions, our work gives practitioners prescriptive guidelines, which assist (though, they do not guarantee) successful IIoT-platform design. Applying these principles enables the development of platforms that foster the emergence of an ecosystem that provides an attractive environment for all stakeholders. As the design principles follow established guidelines in their formulation, they, dedicatedly, prescribe pathways for action that should be easily instantiable. Furthermore, our analysis might help managers of ecosystem participants to better understand the complementors, customers, or the platform owner. This will help them align their activities, strategize, or negotiate more effectively. 


\subsection{Limitations and Outlook}

Our work is subject to limitations. Firstly, design principles, rather than being a guarantee for success, are supporting guidelines that help designers in bringing about an artifact more efficiently. Yet, their instantiation requires stark contextualization with the designer's environment and personal experience [43, 47, 60]. Naturally, as the design principles are the product of a qualitative interview study, they, by their very design, can only cover a delimited spectrum of design areas that were perceived and interpreted as necessary by the authors. The case is fixed on a single firm that was selected based on theoretical considerations, which, even though the case is of high value in representativeness, implies stark borders in generalizability [61].

Lastly, our work is fertile soil for further research. Several requirements indicate that there are many tensions between the different stakeholder-groups in such IIoTplatform ecosystems, whereas their management seems to be of crucial importance. We suggest that future research should pay particular attention to this. It also favors more in-depth analysis, e.g., in the context of a multiple case study, that would span a sample of new firms. That would greatly benefit the generalizability of the results and contribute to painting a much more complete picture.

\section{References}

1. Yoo, Y., Boland, R., Lyytinen, K., Majchrzak, A.: Organizing for Innovation in the Digitized World. Organ Sci 23, 1398-1408 (2012)

2. Guggenberger, T.M., Möller, F., Boualouch, K., Otto, B.: Towards a Unifying Understanding of Digital Business Models. In: Proceedings of the Twenty-Third Pacific Asia Conference on Information Systems. Dubai: United Arab Emirates (2020)

3. Wan, J., Tang, S., Shu, Z., Di Li, Wang, S., Imran, M., Vasilakos, A.: Software-Defined Industrial Internet of Things in the Context of Industry 4.0. IEEE Sens J, 1 (2016)

4. Yaqoob, I., Ahmed, E., Hashem, I.A.T., Ahmed, A.I.A., Gani, A., Imran, M., Guizani, M.: Internet of Things Architecture: Recent Advances, Taxonomy, Requirements, and Open Challenges. IEEE Wirel Commun 24, 10-16 (2017)

5. Boyes, H., Hallaq, B., Cunningham, J., Watson, T.: The industrial internet of things (IIoT): An analysis framework. Comput Ind 101, 1-12 (2018)

6. Chen, B., Wan, J., Shu, L., Li, P., Mukherjee, M., Yin, B.: Smart Factory of Industry 4.0: Key Technologies, Application Case, and Challenges. IEEE Access 6, 6505-6519 (2018)

7. Rochet, J.-C., Tirole, J.: Platform Competition in Two-Sided Markets. J Eur Econ Assoc 1, 990-1029 (2003)

8. Eisenmann, T., Parker, G., van Alstyne, M.: Strategies for two-sided markets. Harvard Bus. Rev. 84, 1-11 (2006)

9. Katz, M.L., Shapiro, C.: Network Externalities, Competition, and Compatibility. Am Econ Rev 75, 424-440 (1985)

10. Jacobides, M., Cennamo, C., Gawer, A.: Towards a Theory of Ecosystems. Strateg Manage J 39, 2255-2276 (2018) 
11. Guggenberger, T.M., Möller, F., Haarhaus, T., Gür, I., Otto, B.: Ecosystem Types in Information Systems. In: Proceedings of the 28th European Conference on Information Systems. Marrakech, Morocco (2020)

12. Parker, G., van Alstyne, M., Jiang, X.: Platform Ecosystems: How Developers Invert the Firm. Mis Quart. 41, 255-266 (2017)

13. Schermuly, L., Schreieck, M., Wiesche, M., Krcmar, H.: Developing an Industrial IoT Platform - Trade-off between Horizontal and Vertical Approaches. In: 14. Internationale Tagung Wirtschaftsinformatik (WI 2019) (2019)

14. Petrik, D., Herzwurm, G.: Towards the IIoT Ecosystem Development - Understanding the Stakeholder Perspective. In: Proceedings of the 28th European Conference on Information Systems. Marrakesh: Morocco (2020)

15. Baldwin, C.Y., Woodard, C.J.: The architecture of platforms. A unified view. Harvard Business School Finance, 1-31 (2008)

16. Schreieck, M., Wiesche, M., Krcmar, H.: Design and Governance of Platform Ecosystems - Key Concepts and Issues for Future Research. In: Proceedings of the 24th European Conference on Information Systems. Istanbul: Turkey (2016)

17. Aulkemeier, F., Iacob, M.-E., van Hillegersberg, J.: Platform-based collaboration in digital ecosystems. Electron Mark 29, 597-608 (2019)

18. Teece, D.J.: Profiting from innovation in the digital economy: Enabling technologies, standards, and licensing models in the wireless world. Res Policy 47, 1367-1387 (2018)

19. Vargo, S.L., Lusch, R.F.: It's all B2B... and beyond: Toward a systems perspective of the market. Ind Market Manag 40, 181-187 (2011)

20. Helfat, C.E., Raubitschek, R.S.: Dynamic and integrative capabilities for profiting from innovation in digital platform-based ecosystems. Res Policy 47, 1391-1399 (2018)

21. Lusch, R., Nambisan, S.: Service Innovation: A Service-Dominant Logic Perspective. Mis Quart. 39, 155-175 (2015)

22. Gawer, A.: Bridging differing perspectives on technological platforms: Toward an integrative framework. Res Policy, 1239-1249 (2014)

23. Wang, S., Wan, J., Zhang, D., Di Li, Zhang, C.: Towards smart factory for industry 4.0: a self-organized multi-agent system with big data based feedback and coordination. Comput Netw 101, 158-168 (2016)

24. Reuver, M. de, Sørensen, C., Basole, R.C.: The Digital Platform: A Research Agenda. J Inf Technol 33, 124-135 (2017)

25. Ghazawneh, A., Henfridsson, O.: Balancing platform control and external contribution in third-party development: the boundary resources model. Inform Syst J 23, 173-192 (2013)

26. Tiwana, A.: Evolutionary Competition in Platform Ecosystems. Inform Syst Res 26, 266$281(2015)$

27. Van Alstyne, M.W., Parker, G., Paul Choudary, S.: Pipelines, platforms, and the new rules of strategy. Harvard Bus. Rev. 2016, 54-62 (2016)

28. Petrik, D., Herzwurm, G.: Boundary Resources for IIoT Platforms-a Complementor Satisfaction Study. In: Proceedings of the 41st International Conference on Information System (2020)

29. Gawer, A., Cusumano, M.A.: Industry Platforms and Ecosystem Innovation. J Prod Innovat Manag 31, 417-433 (2013)

30. Adner, R.: Ecosystem as Structure. J MANAGE 43, 39-58 (2017) 
31. Hagiu, A.: Strategic Decisions for Multisided Platforms. MIT Sloan Manag Rev 55 (2014)

32. Nalebuff, B.J., Brandenburger, A.M.: Co-opetition: Competitive and cooperative business strategies for the digital economy. Strategy \& Leadership 25, 28-33 (1997)

33. Hurni, T., Huber, T.L., Dibbern, J., Krancher, O.: Complementor dedication in platform ecosystems: rule adequacy and the moderating role of flexible and benevolent practices. European Journal of Information Systems 40, 1-24 (2020)

34. Kude, T., Dibbern, J., Heinzl, A.: Why Do Complementors Participate? An Analysis of Partnership Networks in the Enterprise Software Industry. IEEE Trans. Eng. Manage. 59, 250-265 (2012)

35. Schultze, U., Avital, M.: Designing interviews to generate rich data for information systems research. Information and Organization 21, 1-16 (2011)

36. Myers, M.D.: Qualitative Research in Information Systems. MIS Quarterly: Management Information Systems 21, 241 (1997)

37. Patton, M.Q.: Qualitative research \& evaluation methods. Integrating theory and practice. SAGE, Los Angeles, London, New Delhi, Singapore, Washington DC (2015)

38. Krippendorff, K.: Content analysis. An introduction to its methodology. SAGE, Los Angeles, London, New Delhi, Singapore, Washington DC, Melbourne (2019)

39. Mayring, P.: Qualitative content analysis: theoretical foundation, basic procedures and software solution. Klagenfurt (2014)

40. Weber, R.P.: Basic content analysis. SAGE Publications, Newbury Park, Calif. (1990)

41. Brennan, R.L., Prediger, D.J.: Coefficient Kappa: Some Uses, Misuses, and Alternatives. Educ Psychol Meas 41, 687-699 (1981)

42. Landis, J.R., Koch, G.G.: The Measurement of Observer Agreement for Categorical Data. Biometrics 33, 159 (1977)

43. Chandra Kruse, L., Seidel, S., Gregor, S.: Prescriptive Knowledge in IS Research: Conceptualizing Design Principles in Terms of Materiality, Action, and Boundary Conditions. In: Proceedings of the 48th Hawaii International Conference, pp. 4039-4048 (2015)

44. Goldkuhl, G.: Design Theories in Information Systems-a Need for Multi-Grounding. JITTA: Journal of Information Technology Theory and Application 6, 59-72 (2004)

45. Sein, M., Henfridsson, O., Purao, S., Rossi, M., Lindgren, R.: Action Design Research. Mis Quart. 35 (2011)

46. Peffers, K., Tuunanen, T., Rothenberger, M.A., Chatterjee, S.: A Design Science Research Methodology for Information Systems Research. J Manage Inform Syst 24, 45-77 (2007)

47. Möller, F., Guggenberger, T., Otto, B.: Towards a Method for Design Principle Development in Information Systems. In: Proceedings of the 15th International Conference on Design Science Research in Information Systems and Technology (2020)

48. Walls, J.G., Widmeyer, G.R., El Sawy, O.A.: Building an Information System Design Theory for Vigilant EIS. Inform Syst Res 3, 36-59 (1992)

49. Cronholm, S., Göbel, H.: Guidelines Supporting the Formulation of Design Principles. In: Proceedings of the 29th Australasian Conference on Information Systems (2018)

50. Koppenhagen, N., Gaß, O., Müller, B.: Design Science Research in Action - Anatomy of Success Critical Activities for Rigor and Relevance. In: Proceedings of the 20th European Conference on Information Systems, pp. 1-12 (2012) 
51. Möller, F., Guggenberger, T., Otto, B.: Design Principles for Route-Optimization Business Models: A Grounded Theory Study of User Feedback. In: Proceedings of the 15th International Conference on Wirtschaftsinformatik (2020)

52. Economides, N.: The economics of networks. Int J Ind Organ 14, 673-699 (1996)

53. Cennamo, C., Ozalp, H., Kretschmer, T.: Platform Architecture and Quality Trade-offs of Multihoming Complements. Inform Syst Res 29, 461-478 (2018)

54. Doganoglu, T., Wright, J.: Multihoming and compatibility. Int J Ind Organ 24, 45-67 (2006)

55. Belleflamme, P., Peitz, M.: Platform competition: Who benefits from multihoming? Int $\mathbf{J}$ Ind Organ 64, 1-26 (2019)

56. Foerderer, J., Kude, T., Schuetz, S.W., Heinzl, A.: Knowledge boundaries in enterprise software platform development: Antecedents and consequences for platform governance. Info Systems J 29, 119-144 (2019)

57. Täuscher, K., Laudien, S.M.: Understanding Platform Business Models: A Mixed Methods Study of Marketplaces. European Management Journal 36, 319-329 (2018)

58. Reuver, M. de, Nederstigt, B., Janssen, M.: Launch strategies for multi-sided data analytics platforms. ECIS 2018 (2018)

59. Simon, H.A.: The sciences of the artificial. MIT Press, Cambridge, Mass. (1996)

60. Chandra Kruse, L., Seidel, S.: Tensions in Design Principle Formulation and Reuse. In: Proceedings of the 12th International Conference on Design Science Research in Information Systems and Technology (2017)

61. Eisenhardt, K.M.: Building Theories from Case Study Research. The Academy of Management Review 14, 532-550 (1989) 